\title{
To determine the prevalence of hypertension and its lifestyle risk factors in Amhara Region of Debre Birehan Town among Zonal Civil Servants, Ethiopia
}

Solomon Zewdu Wolle ( $\sim$ solomonzewdu94@gmail.com )

St Paul's MMC BIRHAN Maternal and Child Health Surveilance Site https://orcid.org/0000-0001-75900167

Shamble Mengesha Kebed

St Paul's MMC BIRHAN Maternal and Child Health Surveilance Site

Zewdie Aderaw Alemu

GAMBY Medical Business College

Research Article

Keywords: Hypertension, Blood pressure, Zonal sectors

Posted Date: September 30th, 2020

DOI: https://doi.org/10.21203/rs.3.rs-80528/v1

License: (a) (1) This work is licensed under a Creative Commons Attribution 4.0 International License.

Read Full License 
To determine the prevalence of hypertension and its lifestyle risk factors in Amhara Region of Debre Birehan Town among Zonal Civil Servants, Ethiopia.

Solomon Zewdu Wole ${ }^{1 *}$ Shamble Mengesha Kebed ${ }^{2^{*}}$ Zewdie Aderaw Alemu ${ }^{3} \S$

1* Public health specialist at St Paul's MMC BIRHAN Maternal and Chilled Health Surveillance Site Field Supervisors.

2*Public health specialist at St Paul's MMC BIRHAN Maternal and Chilled Health Surveillance Site Field Supervisors

${ }^{1} \S$ PHD program Coordinator at GAMBY Medical Business Collage, Addis Abeba, Ethiopia

*Author

SZW - Email - solomonzewdu94@gmail.com

SMK- Email-shambelmengesha@gmail.com

${ }^{2} \S$ Corresponding Author

Email addresses:zwdie1984@gmail.com 


\section{Abstract}

Background: Hypertension is defined as arterial blood pressure that exceeds 140/90mmhg. Hypertension is one of the most common disease afflicting humans throughout the world. The main objective of this study was to determine the prevalence of hypertension and its risk factors among Debre Berhan Zonal sector civil servants.

Methods: Cross sectional systematic random sampling study were conducted on civil servants of Debre Berhan Zonal sectors by taking a total sample size of 264. And physical measurement based data were collected by investigators through structured and pretested interview administered questionnaire. Results: A total of 259 (98.1\%) participants were included in this study. Prevalence of hypertension was 68(26.2\%) and undiagnosed hypertension was 34 (13.3\%). About $43 \%$ of the respondents reported they had never checked their blood pressure within the past 2 years and above. Factors found to be associated with hypertension include: older age, educational status, family history of hypertension, current cigarette smoker and obesity.

Conclusions and Recommendations: There was high prevalence of both diagnosed and undiagnosed hypertension. There is an urgent need for strategies and program to prevent and control high blood pressure, and promote healthy lifestyle behaviors.

Key words; Hypertension, Blood pressure, Zonal sectors 


\section{Background}

Hypertension means high pressure in the arteries. It is commonly known as high blood pressure. Blood pressure is described by two values, pressure during systole (top value) and pressure during diastole (bottom value). Normal blood pressure is between 90/60 mmHg and 120/80 $\mathrm{mmHg}$. Blood pressure between $120 / 80 \mathrm{mmHg}$ and $139 / 89 \mathrm{mmHg}$ is called pre-hypertension, and a blood pressure of 140/90 $\mathrm{mmHg}$ or above is considered high $[1,4]$.

An elevation of the systolic and/or diastolic blood pressure increases the risk of developing heart disease, kidney disease, hardening of the arteries, eye damage, and stroke. These complications of hypertension are often referred to as end-organ damage because damage to these organs is the end result of chronic high blood pressure $[2,5]$.

Most of the time, hypertensive people show no symptoms in the early stages, symptoms only manifest after end-organ damage. That is why hypertension is described by some clinicians as a 'silent killer'. Symptoms that may occur include chest pain, confusion, ear buzzing, irregular heartbeat, nosebleed, tiredness, and headache and vision changes. [1]

These symptoms are usually a result of end-organ damage and the presentation depends on the organ that is affected. For this reason, the routine screening of symptomatic individuals is critical in early diagnosis, treatment and control of high blood pressure [3, 4].

Early diagnosis, treatment and optimum control of hypertension are keys to reducing morbidity and mortality of hypertension related illnesses. Although the list of causes of hypertension is endless, in more than $90 \%$ of people with hypertension, the cause are not known and is defined as 'essential hypertension' (which means the cause of hypertension cannot be identified) $[5,6]$.

Hypertension is the most important modifiable risk factor for coronary heart disease, stroke, congestive heart failure, end stage renal disease and peripheral vascular diseases. Therefore, health care professionals must not only identify and treat patients with hypertension but also promote a healthy life style and preventive strategies to decrease the prevalence of hypertension in the general population [1, $6]$.

Diagnosis of hypertension is made by the observation of persistently high blood pressure. This needs accurate measurement of blood pressure on at least two different occasions, in each time the individual is given enough time to relax. In very high blood pressure levels ( $\mathrm{SBP} \geq 160 \mathrm{mmHg}$ and/or DBP $\geq 100$ $\mathrm{mmHg}$ ), with evidence of target-organ damage only one reading is necessary to start on treatment [1].

Increasing survivorship rates, especially in urban Ethiopia, are leading to a rise in the number of elderly Ethiopians, and to old-age diseases. Some of these are the so called lifestyle illnesses, normally associated with Western societies where a sedentary life and unhealthy diet has substituted old infections as the major source of morbidity and mortality [2]. 


\section{Statement of the problem}

Hypertension is an important public health challenge, which affects approximately one billion persons worldwide [3]. According to the World Health Organization (WHO), hypertension is the leading risk factor for mortality which is $12.7 \%$ of deaths was attributable [4]. Each year, at least 7.1 million people die as a consequence of hypertension. The overall average prevalence of hypertension in the world was estimated as $35 \%$ (37\% in men and $31 \%$ in women) [3].

Increases in rates of hypertension and other cardiovascular diseases, representing an emerging public health problem in LMICs, happen as populations grow older, become urbanized, and lifestyle changes favor sedentary habits, physical inactivity, obesity, increasing alcohol consumption and salt intake, among others [5].

World Health Organization (WHO) estimated in 2011 that 34\% of Ethiopian population is dying from non-communicable diseases, with a national cardiovascular disease prevalence of $15 \%$, cancer and chronic obstructive pulmonary disease prevalence of $4 \%$ each, and diabetes mellitus prevalence of $2 \%$. Communicable maternal, prenatal and nutritional conditions accounted for $57 \%$ of the deaths. This WHO estimation is comparable with East African countries, such as Kenya, Uganda, and Eritrea [4]. The resulting double burden of non-communicable diseases, with higher prevalence of pre-existing communicable, maternal, prenatal and nutritional conditions, constrains the already meager health resources and hinders economic development in Ethiopia [6].

\section{Justification/ Rational of the study}

One of the most dangerous aspects of hypertension is that we may not know for long time that we have it, until some of our vital organs are damaged. Lifestyle modification is an important and effective first line strategy to prevent and control it.

This study was expected to increase awareness among the population in general, and the subjects of the study in particular, regarding the need to have regular blood pressure checks. Furthermore, the study instills in the minds of people the idea that they can keep their blood pressure under control by adapting the right lifestyle: adjusting salt in the diet, getting regular physical exercise, losing weight if they are obese, avoiding over consumption of alcohols and stopping cigarettes.

The study aimed to give guidance in prioritizing evidence based intervention in the prevention and control of hypertension. There was no information on the prevalence of hypertension, its risk factors and complications among Debre Berhan civil servants. The prevalence of high risk behaviors may assist for health planners in estimating the burden of hypertension in the town. 


\section{METHODS}

\subsection{Study area}

This study was conducted in Debre Berhan town specifically on Debre Berhan Zonal sectors. Debre Berhan is a capital of North Shoa Zone of Amhara Regional State. Debre Berhan is located $710 \mathrm{Km}$ away from Bahir Dar and $130 \mathrm{~km}$ away from Addis Ababa to the North direction in Amhara region. The total population of the town is 86,769 , out of which 39,236 are males and 47,533 are females. There are 648 civil servants in 17 zonal sectors (zonal health bureau, zonal finance and economics bureau, zonal civil service bureau...) in the town from which 443 are males and 205 are females.

\subsection{Study design and period;}

Institution based cross sectional Systematic random sampling study was used for addressing the research problem from September 20, 2019 G.C up to August 20, 2020 G.C.

\subsection{Populations.}

\subsubsection{Source population}

The source population was all Zonal Sectors Civil servants in Debre Berhan town North Shoa Zone, Amhara Region, Ethiopia.

\subsubsection{Study population}

All Zonal Sectors Civil Servant in Debre Berhan town that were selected randomly.

\subsection{Sample size determination and sampling procedure}

\subsubsection{Sample size}

Sample size is determined by the formula $\quad \mathrm{ni}=\mathrm{Z}^{2} \mathrm{pq} / \mathrm{w}^{2}$

$$
\begin{aligned}
& \text { ni= initial sample size } \\
& \mathrm{Z}=1.96(95 \% \text { confidence interval) } \\
& \mathrm{P}=0.32 \text { (finding of Addis Ababa) } \\
& \mathrm{q}=0.68(1-\mathrm{p}) \\
& \mathrm{w}=0.05 \text { (marginal error) } \\
& \mathrm{N}=648
\end{aligned}
$$

$$
\mathrm{ni}=(1.96)^{2}(0.32)(0.68)=334
$$


$(0.05)^{2}$

Calculate final sample size because source of population is $<10,000$

no=final sample size

$$
\mathrm{nf}=\underline{\mathrm{ni}}
$$

$1+\underline{\text { ni }}$

\section{$\mathbf{N}$}

$\mathbf{n f}=\mathbf{2 2 0}$, Adding non response rate $(20 \%)$ of $220=264$

\subsubsection{Sampling technique and procedure}

Using employment registration from each human resource office, we tried to sort all 648 employee by order. Then the total number were divided by 264 (the sample size (n)) to get the interval of selection of 3.The first participant was selected from the first 3 by the lottery method. The subsequent participants were selected by interval of 3 to the select participant. This was done until all 264 participants were selected. Finally we addressed those selected participants on their duty station.

\subsection{Eligibility criteria}

\subsubsection{Inclusion criteria for case control}

$\checkmark$ All Zonal sectors civil servants of Debre Berhan town.

\subsubsection{Exclusion criteria for case and control}

$\checkmark$ Contract workers and employees who had worked for less than six months were excluded from the study.

\subsection{Study variables}

\subsubsection{Dependent variable}

Prevalence of Hypertension among civil servants

\subsubsection{Independent variable}

\section{Socio- demographic variables}

- Age

- $\operatorname{Sex}$

- Education level

- Religion 
Personal variables

○ BMI

- Family history of hypertension

- History of DM

\section{Behavioral variables}

- Salty diet

- Smoking

- Alcohol

- Obesity

- Sedentary life style

\subsection{Operational definitions.}

Awareness of hypertension: Knowing or remembering that the individual was previously diagnosed of hypertension or was told that his/her blood pressure was raised by a health care worker (even without remembering the actual values of systolic and diastolic blood pressure).

Undiagnosed hypertension: Undiagnosed was defined as someone who fitted into the definition of hypertension but was not aware that s/he was hypertensive.

Sedentary life style: is a type of lifestyle with no or irregular physical activity.

Immediate family: participants' parents, grandparents, siblings were defined as immediate family member.

Determinant: Factors or causes that affect hypertension to happen

\subsection{Data collection and quality}

The participants (household head women age 15-24 years ) was interview using a pre-tested standard structured questionnaire which is prepared in English and translated to local language(Amharic). The questionnaire was containing questions on socio-demographics, socioeconomic status, education, religion, and socio-cultural factor. The questionnaires were adapted and modified from previous similar literature after considering the local situations [18, 19]. Data was collect starting from August to December 2019.

\subsection{Data collection procedure}

Before going to the data collection, pretest was done on $5 \%$ of the total sample and based on the findings of the pre-test the questions was utilizing in modifying the questionnaire. All data collectors and supervisor was discussing for two day on their responsibilities for describing the purpose of the study, how to collect the data and telling clients the importance of honest and 
genuine reply on responding to questions. To ensure privacy, interviews was conducting in private rooms or private spaces outside the house before the data collation written consent was taken from all participant. The principal investigators was strictly follow the overall activities of the data collection on daily basis to ensure the completeness of questionnaire and to give further clarification.

\subsection{Data management and analysis}

All filled questionnaires was checked for completeness and consistency, and double data entry was made using the Epidata 3.1 software. Then the data was exported to the SPSS statistical package version 26 for further analysis. Data gathered from the study were analyzed according to WHO definition of Hypertension.

Prior to analysis the assumptions of chi-square test were checked. When smaller expected frequencies were encountered, re-categorization of variables or merger of the levels was made. Factors associated with Hypertension were identified using bivariable and multivariable logistic regression models. Independent variables that demonstrated near to statistically significant association ( $\mathrm{p}$-value less than 0.25 ) with the outcome variable in the bivariable models, were considered as candidate variables for the multivariable logistic regression models. In the ultimate multivariable models the level of multicolinearity was evaluated using variance inflation factor and found within a tolerable range. The goodness-of-fit assessed using Hosmer-Lemeshow test.

Frequencies, proportion, and summary statistics was used to describe the study population in relation to relevant variables and presented in tables afterward; bivariate analysis was carried out to identify candidate variables for the multivariable regression analysis. Then, to identify the predictors of low birth weight, only variables that was significantly associated in the bivariate analysis was entered into multinomial regression. Interactions between different variables Value of $\mathrm{P}<0.05$ was considered statistically significant. The results are reported as odds ratios (AORs) with 95\% confidence interval.

\subsection{Ethical consideration}

Ethical clearance was obtained from the Debre Birehan University Department of Master of public health, Institution Research Ethics Committee (IRERC) to conduct the study.by this Reference number DBU/DPH/472/2019. Further permission was obtained from North Showa Zone administrative Office. The respondent was told about purpose, procedure and benefits of the study to encourage provision of honest and accurate responses. The participant was 
informed that participation is voluntary and confidentiality and privacy of information also secured. Finally written consent was obtained from each participant and privacy was maintained during the interview.

\section{RESULT}

\subsection{Socio demographic characteristics}

A total of 259 civil servants ( $98.1 \%$ response rate) were included in this study. Age of the participants ranged from 24- 60 years. About $48 \%$ were between the age group 41-50. Majority of the respondents $(69.11 \%)$ were males. Two hundred thirty $(88.8 \%)$ were married and majority of the respondents $(85.7 \%)$ were orthodox. Majority of the respondents $53.2 \%$ were gained average monthly salary ranged from 2001-3500 Eth birr. The rest of socio demographic result is shown in the table below about 43\% of the participants had never checked their blood pressure for the last two years and above. The overall prevalence of hypertension was $26.2 \%$ and undiagnosed hypertension was $13.3 \%$. The prevalence of hypertension was higher among males (42.1\%) than females (23.1\%). The disease was seen in $20.5 \%$ of the age group $21-40$ and in $41.2 \%$ of the age group between $51-60$ years of age, $66.18 \%$ were having first degree, $82.3 \%$ were orthodox and $61.8 \%$ had an average monthly income ranged 2001-3500 Eth. Birr [Table 1].

\subsection{Behavioral and dietary related risk factors}

\section{Smoking status}

Majority of the respondents $237(91.9 \%)$ are described as never smoked followed by 5 and $17(6.17 \%)$ which are described ex-smoker and current smoker respectively. Respondents were asked when they smoke and the result has shown majority (67\%) of them started smoking as early as the age of 20 years. This was more common with the age group of 51-60. It was observed that they smoked between 1 and 8 pieces of cigarettes per day while most of the respondents (82\%) smoked between 4 and 6 pieces of cigarettes and was found most among respondents with age group of 51-60. It was also observed that none of women are never smoked cigarette in their life time. All of the respondents 259(100\%), express a negative perception about smoking, hence they indicated that smoking is considered not good but rather harmful [2].

\section{Drinking status}

The overall prevalence of alcohol consumption was (37) 14.2\% among males and 2.7\% (7) among females. Among respondents within age group of 51-60, $10.8 \%$ were current drinkers as against 3.2\% ex-drinkers and $82.6 \%$ had not drunk before. Majority of the respondents among current drinkers (74.1\%) drink once per day [2]. 


\section{Dietary intake of salt}

Dietary intake of salt has not been measured in this research as a result of salt is usually added in the process of cooking foods, rather than in the plate. Fruits were not part of the regular diet but more commonly consumed during weekends, social occasion and holidays [2].

\section{Family history}

To obtained information on hypertension and diabetes presence among family set up, respondents were asked if any known family member is either hypertensive or diabetic. Respondents were expected to indicate 'Yes' or 'No' for presence of hypertension or diabetes in a family setting respectively .From participants $42(16.2 \%)$ had an immediate family member with a history of hypertension and $27(64.3 \%)$ were females. About $61 \%$ of respondents who had family history of hypertension were prevalence to hypertension. From participants 16 (6.17\%) had family history of diabetes [2].

\section{Physical Inactivity}

The overall prevalence of physical inactivity was 86 (33.2\%), with $67.7 \%$ in females and $35.5 \%$ in males. Of the 173 who were physically active, 113(65.3\%) were general hand workers and the activity was experienced mainly at work. Only $11(6.4 \%)$ participants do significant activity (more than 30 minutes of moderate or vigorous activity $2-3$ days/week) at home or during leisure time and $49(28.3 \%)$ while traveling to and from places [2].

\section{Body Mass Index (BMI)}

This is a measure of nutritional status whereby the body weight in Kilogram is divided to the square meters for height. The majority had normal BMI $64.4 \%$ while $4.2 \%$ were obese. Overweight were $18.2 \%$ and were about $31 \%$ among males and $69 \%$ among female [2].

\section{Factor associated to Hypertension}

Among socio-demographic factors age, educational status and family history of hypertension were associated with hypertension. Respondents with the age group 51-60 years were almost five times $(\mathrm{OR}=4.88,95 \% \mathrm{CI}$; 2.24-10.69) more likely to have hypertension as compared with 21-40 years of age. Also respondents within the age group 41-50 years were also 1.3 times (OR=1.3, 95\% CI; 0.612.57)more likely to have hypertension as compared with $21-40$ years of age but which is not statistically significant $(\mathrm{p}=0.54)$. The odd of developing hypertension is 5.6 times $(\mathrm{OR}=5.695 \% \mathrm{CI} ; 1.00-31.32)$ higher among the respondents with educational levels of postgraduate than those who had completed grade eight.

Male participants were $1.83(\mathrm{OR}=1.8395 \% \mathrm{CI} ; 0.95-3.48)$ times more prevalent to hypertension than females but it is not statistically significant (p value 0.07 ). 
Participants who were currently smoking cigarettes are 6.1 times $(\mathrm{OR}=6.1,95 \% \mathrm{CI} ; 2.16-17.25)$ more likely have hypertension than those who never smoked. People who reported having immediate family history of hypertension were 10 times $(\mathrm{OR}=10.1,95 \% \mathrm{CI}$; 4.87-21.07) more likely to have hypertension than those who don't have. The study also revealed that respondents with obesity and overweight were $8.7(\mathrm{OR}=8.795 \% \mathrm{CI} ; 2.63-28.94)$ and $2.2(\mathrm{OR}=2.295 \% \mathrm{CI}$; 1.13-4.44) times more likely to have hypertension as compared to normal body mass index [2].

\section{Discussion}

The study revealed that the prevalence of hypertension among the subject was $26.2 \%$. This result was comparable with a research conducted in Addis Ababa, Ethiopia which reported a 31.5\% and 28.9\% prevalence of hypertension among males and females, respectively (9). It is also comparable with the research conducted in Gonder city (28.3\% prevalence of hypertension) and Jimma University Specialized Hospital 23.7\% $(10,16)$. However prevalence of hypertension in this study is considerably higher as compared to previous reports from Mekele (11\%) and Eretria (15\%). This discrepancy may be explained, this study was conducted only in an urban setting while the above two research's conducted survey for general populations including rural setting. Higher prevalence of hypertension in urban cities compared to rural setting was reported in Jimma study [10].

The result of our study show that increased in age is associated with the prevalence of hypertension. Hypertension was seen of a 5\% among the age group 51-60 compared to 21-40. Similar findings on association of hypertension with age were reported by the survey in Mekelle, and consistent with global trend [17]. This is mainly due to arterial stiffness as one gets older.

Education also plays a very significant role in the prevalence of hypertension. This study observed relatively higher prevalence of hypertension among those who completed postgraduate level (54\%) and those who completed grade eight (17.6\%). This shows being educated at postgraduate level is $5.6 \%$ more hypertensive compared to those who completed grade eight. The finding was consistent with the study conducted in Gondar and Mekele[16,17].

This study failed to show association between hypertension and sex ( $\mathrm{p}$-value $=0.07)$. This result was supported by from previous researches conducted in Mekele, Ertira and Addis Ababa [17, 13, and 15].

Family history also played a significant role in prevalence of hypertension (91\%). This stresses is importance in susceptibility to hypertension and the need for regular screening in this high risk group. Family history of hypertension was higher in females than males. However in hypertension prevention programs, more emphasis should be put on behavioral factors which can be modified and yield greater impact than concentrating on familial and genetic factors.

Cigarette smoking was also a risk factor for hypertension among civil servant employees. A person's risk of heart attack greatly increases with the number of cigarettes he or she smokes and the longer a 
person smokes, the greater their risk of hypertension. People who smoke a pack of cigarettes a day have more than twice the risk of hypertension than non-smokers (1.69\%). In this study, overall prevalence of cigarette smoking was (3.6\%). This result is slightly lower than the study conducted Addis Ababa, Ethiopia of which $4.5 \%$ prevalence rate among males and $1 \%$ among females was observed compared to the current study [13].

\section{Conclusions}

The study found that hypertension prevalence among participants was high $(26.2 \%)$. The prevalence was higher increased with age and postgraduate educational status. The risk factors for hypertension were family history of hypertension, current tobacco smoking, and obesity. However this research failed to show relation of sex, drinking alcohol, salt intake and physical inactivity to prevalence of hypertension.

\section{Recommendations}

$\checkmark$ The Zonal Health Bureau should make this chronic illness a part of public health agenda and set up a program for health education and promotion of awareness and treatment of hypertension.

$\checkmark$ Health care providers in collaborate with Zonal Health Bureau should do public blood pressure screening so that the public could be aware of its blood pressure status.

$\checkmark$ Civil sectors should give support to their employees on information pre-employment and periodic medical examination to assess prevalence and risk factors and then recorded and regularly analyzed. This may serve as a system to monitor the prevalence of hypertension and risk factors and used to evaluate interventions put in place. 


\section{ABBREVIATIONS}

BMI- Body Mass Index, DBP- Diastolic Blood Pressure, HBP-High blood pressure, LMICs -Low Medium Income Countries, MmHg- Millimeter of Mercury, NIAD- Non Infectious Adult Diseases, SBP- Systolic Blood Pressure, SSA-Sub-Seharan Africa, WHO-World Health organization.

\section{Ethical approval and consent}

Ethical clearance was obtained from the Debre Birehan University Department of Master of public health, Institution Research Ethics Committee (IRERC) to conduct the study. Approval was obtained from all hospital.

The respondent was told about purpose, procedure and benefits of the study to encourage provision of honest and accurate responses.

The participant was informed that participation is voluntary and confidentiality and privacy of information also secured. Finally informed verbal consent was obtained from each participant and privacy was maintained during the interview.

\section{Consent for publication}

Not applicable.

\section{Availability of data and materials}

Data supporting the conclusions of this article are available by request to Solomon Zewdu. The relevant raw data will be made available to researchers wishing to use them for non-commercial purposes.

\section{Competing interests}

The author declare that he have no competing interests.

\section{Funding}

Not applicable.

\section{Author's contributions}

SZW and wrote the research proposal, analyze the data, wrote the paper and interpret the findings as well as prepare the manuscript as well as supervise the data collection and train data collectors. 
ZAA advised the whole work during proposal and thesis preparation and also participated on the preparation of the manuscript. Both read and approved the final manuscript.

\section{Acknowledgement}

The author would like to acknowledge to Wro Almaze Abebe, Debre Birehan University Department of Public health for ethical approval, North Show Zonal Tarema Ber Woreda administrative body and our advisor Dr Zewdie Aderaw Alemu. All data collectors are acknowledged for their cooperation during data collection.

Solomon Zewdu Wole ${ }^{1^{*}}$ Shamble Mengesha Kebed ${ }^{2^{*}}$

1* Public health specialist at St Paul's MMC BIRHAN Maternal and Chilled Health Surveillance Site Field Supervisors.

2*Public health specialist at St Paul's MMC BIRHAN Maternal and Chilled Health Surveillance Site Field Supervisors

${ }^{2} \S$ PHD program Coordinator at GAMBY Medical Business Collage, Addis Abeba, Ethiopia

*Correspondence

Zewdie Aderaw Alemu ${ }^{3} \S$

\section{Supplementary file (Additional file)}

This file contains no other data. 


\section{DECLARATION}

$\mathrm{I} / \mathrm{We}$, the under signed, declared that this is my/his original work, has never been presented in this or any other University, and that all the resources and materials used for the thesis work, have been fully acknowledged.

\section{Name of student:}

Name Solomon Zewdu Wole_and Date:_September 9/2020

This thesis has been submitted for examination with my approval as the student thesis work advisor.

Name of advisor: _Shamble Mengesha Kebed_ Date: September 12/2020 emaile shambelmengesha@gmail.com

This thesis is approved by program coordinator.

Name of coordinator: _Zewda Aderaw Alemu _ Date: August 10/2020 email = zwdie1984@gmail.com 


\section{Reference}

1. Fauci S, , Longo DL, Jameson JL et al. Harrison's principles of Internal Medicine. 17th Ed. The McGraw-Hill Companies. 2008

2. F. Tesfaye. Association of Smoking and Khat (Catha edulis Forsk) Use with High Blood Pressure among Adults in Addis Ababa, Ethiopia, 2006, Accessed from Google.com. Accessed on January 28, 2015.

3. Hypertension. Wikipedia, the free encyclopedia. Available on URL http://en.wikipedia.org/wiki/Hypertension\#cite_note-pmid7707630-121 (accessed on 23

January 2015)

4. World Health Organization. 2008-2013 Action Plan for the Global Strategy for the Prevention and Control of Non-communicable Diseases. World Health Organization, 2008

5. Factors that contribute to High Blood Pressure. The American Heart Association.Available on: http://www.americanheart.org/presenter.jhtml?identifier=4650 (Accessed on 15 March 2015)

6. World Health Organization. Global status report on non-communicable diseases 2010. Geneva: World Health Organization, 2011. 162 p.

7. World Health Organization. Global health risks: mortality and burden of disease attributable to selected major risks. Geneva: World Health Organization, 2009. 62 p.

8. Global burden of hypertension may reach 1.5 billion by 2025. Medscape Public Health and Prevention Available from URLhttp://www.medscape.com/viewarticle/538629 (accessed on 20 January 2015)

9. Tesfaye F, Byass P, wall S: Population based prevalence of high blood pressure among adults in Addis Ababa: uncovering a silent epidemic. BMC cardiovascular discord 2009

10. Essayas K, Yadani M, Sahilu A: prevalence of hypertension and its risk factors in Southeast Ethiopia: a hospital-based cross-sectional survey, Acessed from www.dovepress.com. Accessed on December 21, 2014.

11. Seedat YK: Recommendations for hypertension in Sub-Saharan Africa. Cardio Vasc K.S Afr 2004,15:157-158

12. Damasceno A, Avezedo A, Silva matos C, Prista A: Hypertension prevalence, awareness, treatment, and control in Mozambique: urban/rural gap during epidemiological transition. Hypertension 2009,54(1):77-83

13. J Mufunda1, The prevalence of hypertension and its relationship with obesity: results from a national blood pressure survey in Eritrea, Accessed from Google.com. Accessed on December 21, 2014. 
14. Lulu K. Determinants and causes of adult mortality in Butajira. Piazza: Addis Ababa University, 2000. $132 \mathrm{p}$.

15. Misganaw A, Mariam DH, Araya T. The double mortality burden among adults in Addis Ababa, Ethiopia, 2006-2009. Prev Chronic Dis 2012; 9: E84.

16. Akilew A, Tadesse A, Shitaye A, Berihun M: prevalence and associated factors of hypertension among adults in Gondar. BMC cardiovascular discords 2012, 12:13

17. Assefa B, Haftu B, Alemayehu B: Prevalence and associated factors of hypertension among adult population in Mekele city, Northern Ethiopia, Accessed from www.jipst.com. Accessed on December 21, 2014.

Table 1: Socio-demographic characteristics of DebreBirhan city civil servant employees, 2019G.C 


\begin{tabular}{|c|c|c|}
\hline \multicolumn{3}{|l|}{ Sex } \\
\hline Male & 179 & 69.11 \\
\hline Female & 80 & 30.89 \\
\hline \multicolumn{3}{|l|}{ Age (years) } \\
\hline $21-40$ & 80 & 30.89 \\
\hline $41-50$ & 124 & 47.8 \\
\hline $51-59$ & 55 & 21.31 \\
\hline \multicolumn{3}{|c|}{ Educational status } \\
\hline $8^{\text {th }}$ grade & 17 & 6.6 \\
\hline Diploma & 74 & 28.6 \\
\hline First degree & 157 & 60.6 \\
\hline Post graduate & 11 & 4.2 \\
\hline \multicolumn{3}{|l|}{ Marital status } \\
\hline Married & 229 & 88.8 \\
\hline Widowed & 8 & 3.1 \\
\hline Divorced & 3 & 1.1 \\
\hline \multirow[t]{2}{*}{ Single } & & 7 \\
\hline & 18 & \\
\hline \multicolumn{3}{|l|}{ Religion status } \\
\hline Orthodox & 222 & 85.7 \\
\hline Muslims & 16 & 6.2 \\
\hline Protestant & 21 & 8.1 \\
\hline \multicolumn{3}{|c|}{ Monthly income } \\
\hline$<=2000$ birr & 54 & 20.9 \\
\hline 2001-3500 & 138 & 53.2 \\
\hline
\end{tabular}




\begin{tabular}{lcc}
\hline$>3500$ & 67 & 25.9 \\
& & \\
\hline
\end{tabular}

Table 2: factors associated with hypertension among Debre Berhan city civil Servant employees, 2019.

\begin{tabular}{|c|c|c|c|c|c|c|}
\hline \multirow[t]{2}{*}{ variables } & \multirow[t]{2}{*}{ categories } & \multicolumn{2}{|c|}{ Hypertension } & \multirow[b]{2}{*}{$\begin{array}{l}\text { Odds } \\
\text { ratio }\end{array}$} & \multirow[t]{2}{*}{$95 \% \mathrm{Cl}$} & \multirow[t]{2}{*}{$P$ value } \\
\hline & & Yes & No & & & \\
\hline \multirow[t]{2}{*}{ Sex } & Male & 53 & 126 & 1.82 & $0.95-3.48$ & 0.07 \\
\hline & Female & 15 & 65 & & & \\
\hline \multirow[t]{3}{*}{ Age } & $21-40$ & 14 & 66 & 1.00 & & \\
\hline & $41-50$ & 26 & 98 & 1.3 & $0.61-2.57$ & 0.54 \\
\hline & $51-60$ & 28 & 27 & 4.88 & $2.24-10.69$ & 0.0001 \\
\hline \multirow{4}{*}{$\begin{array}{l}\text { Educational } \\
\text { status }\end{array}$} & $8^{\text {th }}$ grade & 3 & 14 & 1.00 & & \\
\hline & Diploma & 14 & 60 & 1.1 & $0.28-4.31$ & 0.90 \\
\hline & First degree & 45 & 112 & 1.87 & $0.51-6.84$ & 0.34 \\
\hline & Post graduate & 6 & 5 & 5.6 & $1.00-31.32$ & 0.04 \\
\hline \multirow[t]{4}{*}{ Marital status } & Single & 4 & 14 & 1.00 & & \\
\hline & Married & 61 & 168 & 1.27 & $0.40-4.01$ & 0.68 \\
\hline & Widowed & 2 & 6 & 1.17 & $0.17-8.19$ & 0.88 \\
\hline & Divorced & 1 & 2 & 1.75 & $0.12-24.65$ & 0.68 \\
\hline \multirow{3}{*}{$\begin{array}{l}\text { Religion } \\
\text { status }\end{array}$} & Orthodox & 56 & 166 & 1.00 & & \\
\hline & Muslims & 4 & 12 & 0.99 & $0.31-3.19$ & 0.98 \\
\hline & Protestant & 8 & 13 & 1.82 & $0.72-4.63$ & 0.21 \\
\hline
\end{tabular}




\begin{tabular}{|c|c|c|c|c|c|c|}
\hline \multirow{3}{*}{$\begin{array}{l}\text { Monthly } \\
\text { income }\end{array}$} & $<=2000$ birr & 10 & 44 & 1.00 & & \\
\hline & 2001-3500 birr & 42 & 96 & 1.93 & $0.89-4.18$ & 0.098 \\
\hline & $>3500$ birr & 16 & 51 & 1.38 & $0.57-3.35$ & 0.476 \\
\hline \multirow[t]{3}{*}{ Smoking } & Never smoked & 55 & 182 & 1.00 & & \\
\hline & Current smoker & 11 & 6 & 6.1 & $2.16-17.25$ & 0.0006 \\
\hline & Ex-smoker & 3 & 2 & 5.0 & $0.81-30.63$ & 0.08 \\
\hline \multirow[t]{3}{*}{ Drinking } & Never drink & 49 & 141 & 1.00 & & \\
\hline & Current drinker & 13 & 31 & 1.2 & $0.58-2.49$ & 0.61 \\
\hline & Ex-drinker & 6 & 19 & 0.9 & $0.34-2.41$ & 0.85 \\
\hline \multirow{5}{*}{$\begin{array}{l}\text { Physical } \\
\text { inactivity }\end{array}$} & No activity & 32 & 54 & 1.58 & $0.39-6.39$ & 0.52 \\
\hline & General hand work & 26 & 87 & 0.80 & $0.19-3.22$ & 0.75 \\
\hline & 10 min walk & 7 & 42 & 0.44 & & \\
\hline & $30 \mathrm{~min}$ vigorous & 3 & 8 & & $0.09-2.09$ & 0.31 \\
\hline & activity & & & 1.00 & & \\
\hline \multirow[t]{2}{*}{ Family history } & No & 30 & 187 & & & \\
\hline & Yes & 26 & 16 & 10.1 & $4.87-21.07$ & $<0.0001$ \\
\hline \multirow[t]{4}{*}{ BMI } & Underweight & 2 & 33 & 0.19 & $0.04-0.83$ & 0.028 \\
\hline & Normal & 40 & 127 & 1.00 & & \\
\hline & Overweight & 19 & 27 & 2.2 & $1.13-4.44$ & 0.021 \\
\hline & Obese & 11 & 4 & 8.73 & $2.63-28.94$ & 0.0004 \\
\hline
\end{tabular}


21 P a g e 


\section{Supplementary Files}

This is a list of supplementary files associated with this preprint. Click to download.

- QusetionerHayper.pdf 